\title{
Enfoque del paciente con adenopatías generalizadas. Importancia de la estrategia didáctica del estudio de casos clínicos: a propósito de un paciente con linfoma de Hodgkin asociado a una infección por el virus de Epstein-Barr
}

\author{
Juan Pablo Villegas-Molina', Marianella Yarce-Prince', John Camilo 0choa-Hernández', Sara de Dios Cardona-Muñoz', \\ Laura Victoria Orozco-Beltrán', Elber Ruiz-Hernández', Carolina Cárdenas-Cañas' , Luis Alfonso Correa-Londoño², \\ Carlos José Atencia-Flórez ${ }^{3}$, Margarita Velásquez-Lopera ${ }^{4}$
}

\section{RESUMEN}

Se muestra el caso de un paciente con 56 años de edad, con un síndrome adenomegálico generalizado que presentó un linfoma de Hodogkin de celularidad mixta, asociado al virus de Epstein-Barr. El paciente previo al inicio del linfoma presentó episodios prolongados de estrés emocional, lo que posiblemente contribuyó a la disminución de la vigilancia inmunológica. El caso fue abordado por los estudiantes de quinto semestre en la asignatura Acto médico, una estrategia didáctica interdisciplinaria. Este artículo presenta los aspectos a tener en cuenta en el enfoque clínico de los pacientes con adenopatías desde una perspectiva integradora de la inmunología, la clínica y los diagnósticos diferenciales. Se resalta el valor del estudio de los casos clínicos con varios métodos diagnósticos como estrategia didáctica. Finalmente, se realiza una revisión de la literatura sobre el linfoma Hodgkin orientada al papel en el que participa la infección por el virus de Epstein-Barr, relacionada con la inmunosupresión por estrés.

1 Estudiantes, Facultad de Medicina de la Universidad de Antioquia, Medellín, Colombia.

2 Patólogo, profesor de Dermatopatología, Sección de Dermatología, Centro de Investigaciones Dermatológicas CIDERM, Facultad de Medicina, Universidad de Antioquia, Medellín, Colombia.

3 Médico Internista, Hospital Universitario San Vicente Fundación, profesor del Departamento de Medicina Interna, Facultad de Medicina, Universidad de Antioquia, Medellín, Colombia.

4 Dermatóloga, doctora en Ciencias Básicas Biomédicas-Inmunología, profesora, Sección de Dermatología, Centro de Investigaciones Dermatológicas CIDERM, Facultad de Medicina, Universidad de Antioquia, Medellín, Colombia.

Correspondencia: Margarita María Velásquez Lopera; mmvelasquez@yahoo.com

Recibido: noviembre 16 de 2018

Aceptado: abril 5 de 2019

Cómo citar: Villegas-Molina JP, Yarce-Prince M, Ochoa-Hernández JC, Cardona-Muñoz SD, Orozco-Beltrán LV, Ruiz-Hernández E, et al. Enfoque del paciente con adenopatías generalizadas. Importancia de la estrategia didáctica del estudio de casos clínicos: a propósito de un paciente con linfoma de Hodgkin asociado a una infección por el virus de Epstein-Barr. latreia. 2019 0ct-Dic;32(4):328-337. D0l 10.17533/udea.iatreia.33. 


\section{PALABRAS CLAVE}

Anamnesis; Enseñanza; Estrés EmocionaI; Examen Físico; Informes de Casos; Inmunosupresión; Linfadenopatía; Linfoma de Hodogkin; Infección por el Virus Epstein-Barr

\section{SUMMARY}

Approach of the patient with generalized adenopathies. Importance of the didactic strategy of the study of clinical cases: a purpose of a patient with Hodgkin's lymphoma associated with an infection with the Epstein-Barr virus

We present the case of a 56-year-old patient with a generalized adenomegalic syndrome who presented a mixed cellular Hodgkin's lymphoma associated with Epstein Barr Virus. The patient had had great emotional stress prior to the onset of lymphoma, which possibly contributed to the decrease in immunological surveillance. The case was addressed by the students of the fifth semester in the subject "Medical Act", an interdisciplinary didactic strategy. We present the aspects to be taken into account in the approach of the clinician of patients with adenopathies from an integrative perspective of immunology, clinical and differential diagnoses; and the value of the study of clinical cases with several diagnostic approaches as a didactic strategy is highlighted. Finally, we present a literature review about Hodgkin lymphoma and the role which plays stress related Epstein Barr Virus infection.

\section{KEYWORDS}

Case Report; Epstein-Barr Virus Infections; Hodgkin Disease; Immunosuppression; Lymphadenopathy; Medical History Taking; Physical Examination; Stress, Psychological; Teaching

\section{INTRODUCCIÓN}

En la formación de los estudiantes de Medicina se emplean diversas estrategias didácticas, entre estas, las clases magistrales, los talleres, las prácticas clínicas, las visitas comunitarias, el aprendizaje basado en problemas (ABP), los casos clínicos y las herramientas de teleducación. El estudio de casos clínicos en tiempo real permite un abordaje integral y la articulación de conceptos y saberes aprendidos previamente.

Se presenta el caso de un paciente con síndrome de adenopatía generalizada quien finalmente, fue diagnosticado con linfoma tipo Hodgkin de celularidad mixta, enfocado por un grupo de estudiantes del quinto semestre de Medicina de la Universidad de Antioquia y sus respectivos tutores de las áreas de Medicina interna, Inmunología, Patología y Bioética, dentro del curso Acto médico. Se revisaron los aspectos básicos y clínicos relacionados con el estudio de las adenopatías, la relación de la infección por el virus de Epstein-Barr y el linfoma, así como también la importancia del seguimiento por parte del médico en el cuidado del paciente. Se muestran las aproximaciones diagnósticas por patrones y probabilístico como parte de la estrategia didáctica.

Los estudiantes cuentan con el consentimiento informado por escrito del paciente para el estudio y publicación del caso. Se preserva la confidencialidad y el anonimato de la identidad del paciente.

\section{MÉTODOS Y ESTRATEGIA DEL CASO}

Con el objetivo de acercar los estudiantes a una evaluación integral de sus pacientes, la Facultad de Medicina de la Universidad de Antioquia incluye el estudio de casos en el curso de pregrado Acto médico del $\nabla$ semestre, esta asignatura es el punto de inflexión entre los semestres de ciencias básicas y clínicas. El estudio de casos se lleva a cabo mediante la evaluación completa e integral de un paciente en tiempo real por un equipo de estudiantes del semestre, con la asesoría de un médico internista, un inmunólogo, un patólogo y un experto en bioética.

De los registros de las historias clínicas del sistema SAP del Hospital Universitario San Vicente Fundación se identificaron historias clínicas de pacientes que consultaban en los servicios de urgencias y estaban hospitalizados con la codificación diagnóstica CIE-10: adenopatía generalizada y se seleccionó un caso que no tenía diagnóstico etiológico definitivo, 
se le realizó un seguimiento durante su hospitalización. Previa explicación satisfactoria y firma voluntaria del consentimiento informado de parte del paciente, se les permitió a los estudiantes de quinto semestre en la asignatura Acto médico que entrevistaran al paciente y lo examinaran, sin acceso a la historia clínica, supervisados por un docente. Se continuó la didáctica durante varias sesiones de encuentro entre los estudiantes y el docente donde se discutió el abordaje semiológico del paciente con adenopatías y se analizó la nueva información que emergía durante la hospitalización de este. Posteriormente, se le facilitó a los estudiantes tener varias entrevistas con el paciente para evaluar su evolución, además del acceso a los exámenes de laboratorio e imágenes diagnósticas con lo cual se complementó el análisis y, finalmente, se obtuvo el resultado del diagnóstico definitivo de la biopsia del ganglio en el departamento de Patología. Los estudiantes pudieron hacer el seguimiento y diagnóstico completo del paciente durante la hospitalización con enfoque heurístico y probabilístico. Se efectuó una revisión narrativa corta de la literatura sobre el linfoma tipo Hodgkin, enfatizando el papel en el que participa la infección por virus de Epstein-Barr relacionada con la inmunosupresión por estrés.

\section{RESULTADOS}

\section{Caso clínico}

Paciente masculino con 55 años, viudo y vendedor ambulante, natural de Versalles, Antioquia, reside en Medellín, Antioquia. Consultó por cuadro clínico consistente en astenia, fiebre y emesis de dos meses de evolución, acompañado de hiporexia, adinamia y pérdida de peso subjetiva. Este cuadro clínico inició de manera posterior al fallecimiento de su esposa. El paciente ingresó a un hospital de segundo nivel de atención por fiebre de $40{ }^{\circ} \mathrm{C}$, diaforesis nocturna, emesis, cefalea de predominio frontal de tipo pulsátil, masas en el cuello y axila. Dos meses después fue remitido a un tercer nivel de atención debido a la persistencia del cuadro. Los síntomas incrementaron y se acompañaron de artralgias, cefalea difusa y aumento del tamaño de las masas que limitaban la movilidad del cuello.
A la revisión por sistemas refirió odinofagia, meteorismo, dolor abdominal y prurito en ambos miembros inferiores. No refirió tos o expectoración ni disnea. Como antecedente personal relató diabetes mellitus tipo II, diagnosticada hace 4 años y tratado con metformina, con poca adherencia al tratamiento. Fumador de 3 paquetes de cigarrillos al día por más de 30 años, exposición ocupacional a pesticidas. Respecto a los antecedentes familiares, padre con cáncer pulmonar, madre con osteoartritis y hermanos con enfermedad pulmonar obstructiva crónica, cáncer pulmonar e hipertensión arterial.

En el examen físico se encontró un paciente con buen estado general, orientado, pálido, signos vitales estables, con múltiples adenopatías de 1,5 y $3 \mathrm{~cm}$ de diámetro, indoloras, algunas de ellas con borde eritematoso, ubicadas en el área preauricular, cervical, submentoniana, epitroclear y axilar bilateral, esplenomegalia, aproximadamente, de cuatro centímetros debajo del reborde costal izquierdo. En la piel se observaron vesículas y costras en la comisura de los labios.

El estudio fue enfocado con base en los siguientes diagnósticos sindromáticos: síndrome adenomegálico generalizado, síndrome constitucional, síndrome febril y síndrome anémico. En la (Tabla 1) se resumen los resultados de los paraclínicos y su interpretación. En los estudios imagenológicos, la radiografía AP y lateral de tórax se evidenció una ocupación mediastinal y otra de la ventana aortopulmonar (Figura 1). En la tomografía axial contrastada del cuello se observaron múltiples adenopatías bilaterales en las cadenas ganglionares II, III y V (Figura 1).

En el estudio de las adenopatías se realizó una biopsia de ganglio linfático. En la tinción hematoxilina-eosina se evidenció la distorsión de la arquitectura por proliferación de linfocitos pequeños y células de ReedSternberg, células plasmáticas e histiocitos, presencia de células grandes nucleoladas (Figura 2). El perfil inmunohistoquímico fue consistente con el diagnóstico de linfoma de Hodogkin clásico, celularidad mixta, asociado a la infección por virus de Epstein-Barr (Figura 3). Según la clasificación de Ann Arbor, el estadio del linfoma del paciente corresponde a IVB. EI paciente fue dado de alta para la evaluación ambulatoria por hematología para iniciar quimioterapia, pero hasta la fecha el paciente no regresó a consulta. 

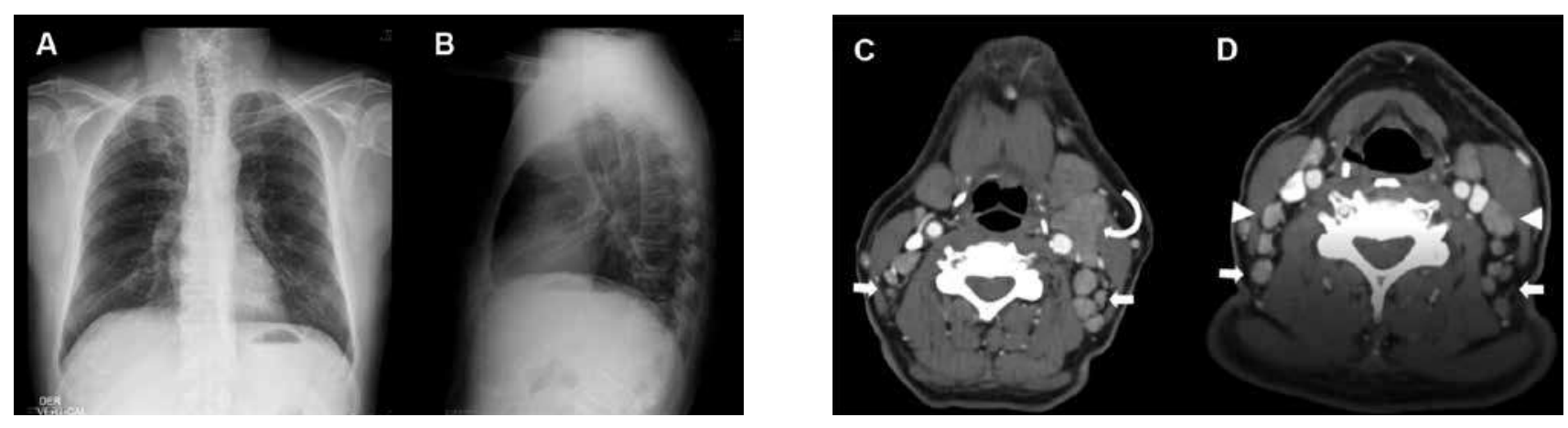

Figura 1. (A y B) Radiografía PA y lateral de tórax. Se observa el ensanchamiento mediastinal y la ocupación de la ventana aortopulmonar (lateral), probablemente por denopatías. No se detectaron cavernas ni micronódulos. (C y D) Tomografía axial contrastada del cuello. Se observan múltiples adenopatías bilaterales en las cadenas ganglionares II (flecha curva), III (cabeza de flecha) y V (flecha recta).Fuente: creación propia.

Tabla 1. Resultados de los exámenes de laboratorio

\begin{tabular}{|c|c|c|c|}
\hline Paraclínico & Hallazgo & Valor & Interpretación \\
\hline \multirow{7}{*}{ Hemoleucograma } & Recuento de plaquetas & $47.000 \mathrm{ul}$ & \multirow{3}{*}{$\begin{array}{l}\text { Pancitopenia: evidencia de infiltración } \\
\text { medular por compromiso del linfoma }\end{array}$} \\
\hline & Recuento de neutrófilos & $300 / u l$ & \\
\hline & Hemoglobina & $10 \mathrm{~g} / \mathrm{dl}$ & \\
\hline & VCM & $87 \mathrm{fL}$ & \multirow{4}{*}{$\begin{array}{l}\text { Anemia normocítica normocrómica } \\
\text { homogénea arregenerativa, sugestiva de } \\
\text { enfermedad crónica }\end{array}$} \\
\hline & $\mathrm{HCM}$ & $38 \mathrm{pg} / \mathrm{mL}$ & \\
\hline & Reticulocitos & $1 \%$ & \\
\hline & ADE & $13 \%$ & \\
\hline \multirow{3}{*}{$\begin{array}{l}\text { Reactantes de } \\
\text { fase aguda }\end{array}$} & Velocidad de sedimentación globular & $90 \mathrm{~mm} /$ hora & \multirow{3}{*}{$\begin{array}{l}\text { Orienta hacia un proceso inflamatorio } \\
\text { sistémico en curso e infiltración del } \\
\text { sistema retículo endotelial }\end{array}$} \\
\hline & PCR & $1,4 \mathrm{mg} / \mathrm{dl}$ & \\
\hline & Ferritina & $>2000 \mathrm{ng} / \mathrm{dl}$ & \\
\hline \multirow{4}{*}{$\begin{array}{l}\text { Extendido de } \\
\text { sangre periférica }\end{array}$} & Hipocromía + & & Anemia \\
\hline & Policromatofilia + & & Anemia \\
\hline & Punteado basófilo + & & Anemia, inflamación \\
\hline & \multicolumn{2}{|c|}{ Distribución plaquetaria: Anormal Observación: disminuidas } & $\begin{array}{l}\text { Trombocitopenia con MPV bajo, sugiere } \\
\text { falta de producción megacariopoyética }\end{array}$ \\
\hline $\begin{array}{l}\text { Deshidrogenasa } \\
\text { láctica }\end{array}$ & \multicolumn{2}{|l|}{$388 \mathrm{UI} / \mathrm{L}$} & $\begin{array}{l}\text { Aumenta debido al daño tisular y/o } \\
\text { recambio de células hematopoyéticas }\end{array}$ \\
\hline ELISA para VIH & \multicolumn{2}{|l|}{ No reactivo } & Permite descartar VIH como etiología \\
\hline $\begin{array}{l}\text { Biopsia de } \\
\text { médula ósea }\end{array}$ & \multicolumn{2}{|c|}{$\begin{array}{l}\text { Relación mieloide eritroide 1:3 eritropoyesis, megacariopoyesis y } \\
\text { mielopoyesis normal. Infiltrado linfoide atípico para caracterizar } \\
\text { en inmunohistoquímica y citometría de flujo }\end{array}$} & $\begin{array}{l}\text { No se descarta la enfermedad } \\
\text { linfoproliferativa de la médula ósea }\end{array}$ \\
\hline
\end{tabular}

Fuente: creación propia. 


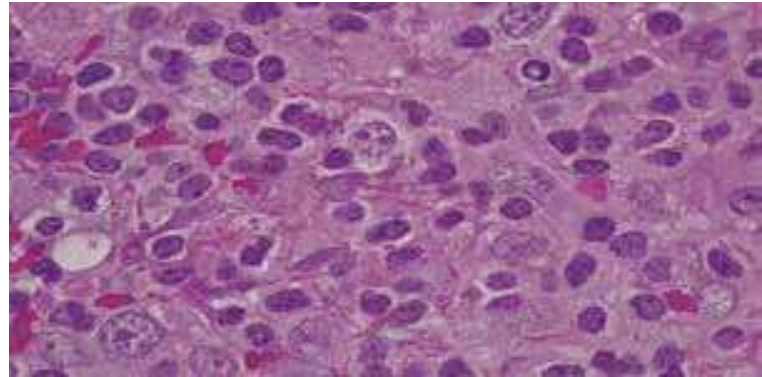

Figura 2. Célula de Red-Sternberg. Bilobulada con mitades en espejo y un gran núcleo con aspecto de "ojo de búho". Hematoxilina eosina $100 \mathrm{X}$. Fuente: creación propia.

\section{DISCUSIÓN}

\section{Estrategia didáctica del estudio de casos clínicos en el enfoque del paciente con adenomegalias ge- neralizadas}

El enfoque clínico de este paciente con adenomegalias turo en cuenta por parte de los estudiantes, aspectos básicos, clínicos y epidemiológicos. Se comparan los métodos de aproximación diagnóstica por reconocimiento de patrones (heurístico) con el análisis de probabilidades (bayesiano) (Tabla 2 y 3 ).
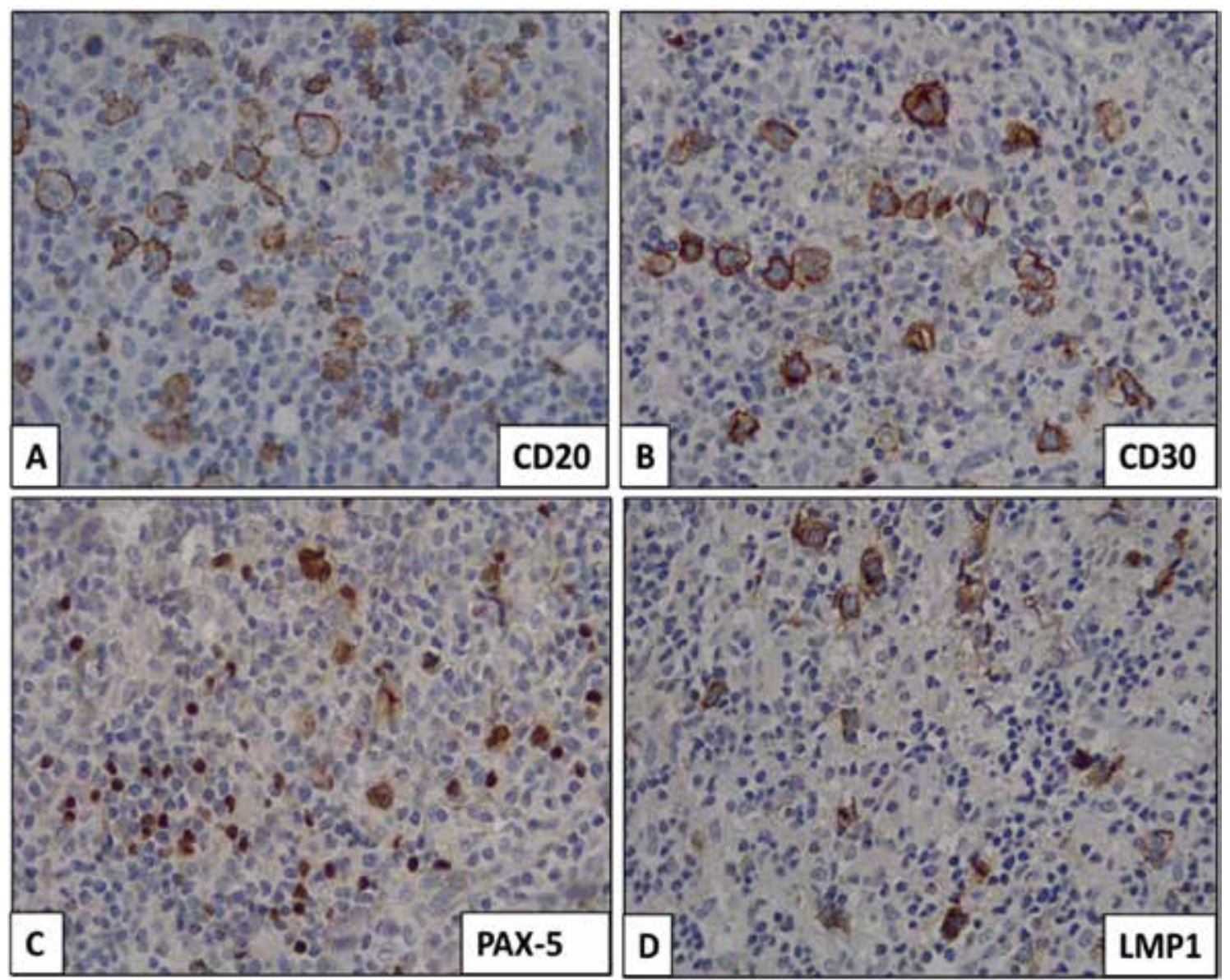

Figura 3. Linfoma de Hodgkin clásico. Asociado al virus Epstein-Barr. Cambios morfológicos en el ganglio linfático con distorsión de la arquitectura y aumento de la celularidad. Inmunohistoquímica para CD20 (A), CD30 (B), PAX-5 (C) y LMP1, proteína latente de membrana del virus de Epstein-Barr (D), positivos en las células de Reed-Sternberg 40X, ganglio linfático. Fuente: creación propia. 
Tabla 2. Examen físico del paciente con adenopatías basado en el reconocimiento de patrones

\begin{tabular}{|c|c|c|c|c|}
\hline $\begin{array}{c}\text { Método } \\
\text { exploratorio }\end{array}$ & \multicolumn{3}{|c|}{ Característica del hallazgo } & Interpretación \\
\hline \multirow{13}{*}{ Inspección } & \multicolumn{3}{|c|}{ Eritema, rasguño en la piel contigua } & Celulitis, bartonelosis \\
\hline & \multicolumn{3}{|c|}{ Secreción blanquecina (caseum) } & Escrófula tuberculosa \\
\hline & \multicolumn{3}{|c|}{ Distorsión del contorno anatómico } & Neoplasia maligna \\
\hline & \multirow{7}{*}{ Localización } & \multicolumn{2}{|c|}{ Retroauricular } & Rubeola, bartonelosis \\
\hline & & \multicolumn{2}{|c|}{ Preauricular } & Síndrome oculoglandular de Parinaud, tracoma \\
\hline & & \multicolumn{2}{|l|}{ Cervical } & $\begin{array}{l}\text { Toxoplasmosis, mononucleosis, linfoma Burkitt, enfermedad de } \\
\text { Kawasaki, enfermedad Rosai-Dorfman }\end{array}$ \\
\hline & & \multicolumn{2}{|l|}{ Axilar } & Silicona, cáncer de mama metastásico \\
\hline & & Epitroclear & Unilateral & Linfoma \\
\hline & & & Bilateral & Sarcoidosis, sífilis, VIH esporotricosis \\
\hline & & \multicolumn{2}{|l|}{ Inguinal } & $\begin{array}{l}\text { Enfermedad de transmisión sexual (cancroide, linfogranuloma } \\
\text { venéreo) melanoma y neoplasia de cérvix y vulva }\end{array}$ \\
\hline & \multirow{3}{*}{$\begin{array}{l}\text { Ganglios } \\
\text { especiales }\end{array}$} & \multicolumn{2}{|l|}{ G. de Delphi } & Neoplasia de tiroides \\
\hline & & \multicolumn{2}{|c|}{ G. de Virchow (Troisser) } & $\begin{array}{l}\text { Derecho: cáncer de pulmón } \\
\text { Izquierdo: cáncer gástrico }\end{array}$ \\
\hline & & \multicolumn{2}{|c|}{ G. de la Hermana María José } & Neoplasia intrabdominal y pélvica \\
\hline \multirow{8}{*}{ Palpación } & Tamaño & \multicolumn{2}{|c|}{$\begin{array}{l}\text { Epitrocleares }(>0,5 \mathrm{~cm}) \\
\text { Axilares y supraclaviculares } \\
(>1 \mathrm{~cm}) \\
\text { Inguinales }(>2 \mathrm{~cm})\end{array}$} & Sugestivos de malignidad \\
\hline & \multicolumn{3}{|l|}{ Dolor } & Enfermedad reactiva o inflamatoria \\
\hline & \multicolumn{3}{|c|}{ Contornos irregulares } & Sugiere neoplasia maligna \\
\hline & \multirow{2}{*}{ Adherencia } & \multicolumn{2}{|c|}{ Planos superficiales } & Enfermedad reactiva, inflamatoria o infecciosa. \\
\hline & & \multicolumn{2}{|c|}{ Planos profundos } & Sugiere neoplasia maligna \\
\hline & \multirow{3}{*}{ Consistencia } & \multicolumn{2}{|c|}{ Dura } & Sugiere neoplasia maligna \\
\hline & & \multicolumn{2}{|l|}{ Blanda } & Enfermedad reactiva o inflamatoria \\
\hline & & \multicolumn{2}{|l|}{ Cauchosa } & Linfomas \\
\hline
\end{tabular}

Tomada de Diagnóstico diferencial en medicina interna, modificado y adaptado con autorización del autor Laso Guzmán F. Javier (10).

Los ganglios linfáticos son órganos linfoides secundarios cuya función primordial es ser el sitio en donde los linfocitos T (LT) vírgenes son activados por las células presentadoras de antígenos tisulares linfáticos, iniciando la respuesta inmune adaptativa, cooperando con los linfocitos B (LB) en su activación y generando centros germinales en los que los LB hacen la maduración de la afinidad, el cambio de isotipo y se convierten en células plasmáticas secretoras de inmunoglobulinas ${ }^{(1,2)}$. Hoy se sabe que el cuerpo humano tiene aproximadamente 600 ganglios linfáticos encargados, en conjunto con el bazo, las adenoides y las placas de Peyer, de depurar antígenos del líquido extracelular como consecuencia de la reacción inflamatoria producida por procesos patológicos en los tejidos, pero solo el $25 \%$ de ellos están ubicados en las regiones submandibulares, axilares o femorales y pueden ser palpados en personas sanas. Los ganglios linfáticos se consideran patológicos cuando miden más de $1 \mathrm{~cm}$ de diámetro (adenopatías), a excepción de los ganglios linfáticos inguinales que se consideran patológicos por encima de $2 \mathrm{~cm}$, los de localización profunda (intratorácicos o intrabdominales) cuando miden más de $1,5 \mathrm{~cm}$ y los epitrocleares cuando miden más de $0,5 \mathrm{~cm}$. En el caso del paciente se solicitó una tomografía de cuello y radiografía de tórax como respuesta a la sospecha de adenopatía generalizada de tamaño significativo, ya que varios sitios no son palpables (mediastino, cuello profundo, hiliares). 
Tabla 3. Predicción de la malignidad de un ganglio linfático mediante cocientes de probabilidad por características clínicas, basado en métodos probabilísticos

\begin{tabular}{|c|c|c|c|c|}
\hline Hallazgo & Sensibilidad & Especificidad & LR + & LR - \\
\hline \multicolumn{5}{|l|}{ Apariencia general } \\
\hline Género masculino & $44-59$ & $49-72$ & 1,3 & 0,8 \\
\hline Edad mayor de 40 años & $48-91$ & $53-87$ & 2,4 & 0,4 \\
\hline Pérdida de peso & $19-28$ & $90-95$ & 3,4 & 0,8 \\
\hline Fiebre & $1-31$ & $60-80$ & NS & NS \\
\hline \multicolumn{5}{|l|}{ Distribución de las adenopatías } \\
\hline Cabeza y cuello & $21-79$ & $15-69$ & NS & NS \\
\hline Supraclaviculares & $8-61$ & $84-94$ & 3,2 & 0,8 \\
\hline Axilares & $8-52$ & $30-91$ & 0,8 & NS \\
\hline Inguinales & $3-22$ & $61-96$ & 0,6 & NS \\
\hline Epitrocleares & 2 & 97 & NS & NS \\
\hline Generalizadas & $32-48$ & $31-87$ & NS & NS \\
\hline \multicolumn{5}{|l|}{ Características de las adenopatías } \\
\hline \multicolumn{5}{|l|}{ Tamaño } \\
\hline$<4 \mathrm{~cm} 2$ & $33-36$ & $9-37$ & 0,4 & - \\
\hline $4-8,9 \mathrm{~cm} 2$ & $26-30$ & - & NS & - \\
\hline$>9 \mathrm{~cm} 2$ & $37-38$ & $91-98$ & 8,4 & - \\
\hline Consistencia dura & $48-62$ & $83-84$ & 3,2 & 0,6 \\
\hline Dolor & $3-18$ & $50-86$ & 0,4 & 1,3 \\
\hline Adherencia & $12-52$ & 97 & 10,9 & NS \\
\hline Puntaje combinado de los anteriores hallazgos con mejor desempeño & 56 & 99 & 21,9 & 0,04 \\
\hline
\end{tabular}

Tomada de: McGee S. Evidence Based Physical Diagnosis. 3. Ed. Filadelfia: Elsevier Saunders; 2012. NS: no se especifica el dato en el estudio

Las linfadenopatías pueden ser causadas por una amplia gama de enfermedades y medicamentos. La ubicación de la linfadenopatía a menudo se puede usar para ayudar a identificar etiologías específicas ${ }^{(3)}$. Se define como localizada cuando compromete solo una cadena ganglionar como el cuello o la axila, estas incluyen el $75 \%$ de los casos, casi siempre causada por una enfermedad específica en el área de drenaje. En cambio, se define como generalizada cuando están afectadas dos o más cadenas ganglionares, estas representan el $25 \%$ restante y casi siempre indican el signo de una enfermedad sistémica como las enfermedades neoplásicas, infecciosas, reactivas, por depósito y autoinmunes ${ }^{(3-7)}$. En el caso que se presenta, no había ninguna exposición a medicamentos, historia familiar sugestiva, ni síntomas o signos que indicaran una enfermedad autoinmune.

En la identificación del paciente, su edad, género y raza pueden ayudar a centrarse en las posibilidades diagnósticas. Así en los niños (rubeola, mononucleosis infecciosa, enfermedad de Kawasaki), mujeres jóvenes (lupus eritematoso sistémico, enfermedad de Kikuchi), los ancianos (cáncer y linfomas no Hodgkin) $y$ afrodescendientes (sarcoidosis) presentan con mayor probabilidad ciertas enfermedades. Nuestro paciente era un hombre joven donde el linfoma de Hodgkin, la tuberculosis y el VIH eran importantes.

Las exposiciones también pueden arrojar pistas diagnósticas. Como un rasguño de gato (enfermedad de rasguño de gato), mordedura de ratas (sodoku), contacto con liebres y conejos (tularemia), consumo de carne poco cocida (toxoplasmosis), picadura de garrapata (enfermedad de Lyme), viajes a áreas con altas tasas de infección endémica y comportamiento de alto riesgo (conducta sexual, uso de drogas inyectables). Síntomas constitucionales como la fiebre, sudores nocturnos o pérdida de peso que sugieren tuberculosis, 
linfoma u otra neoplasia maligna; la fiebre suele acompañar a las linfadenopatías en la mayoría de las etiologías infecciosas y linfomas. Uso de medicamentos que pueden causar linfadenopatía ${ }^{(8)}$, ejemplo: alopurinol, carbamazepina, hidralazina, fenitoína. Finalmente, los viajes al extranjero, que deben extender el diagnóstico diferencial a enfermedades que de otra manera no ocurren localmente (Leishmaniasis visceral). Nuestro paciente no esturo expuesto a animales, zonas endémicas o contactos enfermos.

También se debe realizar un examen físico completo para buscar signos de la enfermedad sistémica, por ejemplo; la esplenomegalia asociada sugiere linfoma, leucemia linfocítica crónica, tricoleucemia, leucemia aguda, leucemia prolinfocítica o mononucleosis infecciosa ${ }^{(7,8-9)}$. Las erupciones en la piel deben hacer pensar en rubeola (rash súbito cefalocaudal), sífilis (chancro o secundaria compromiso en almas), enfermedad del suero (rash morbiliforme), VIH (Kaposi y otros oportunistas) y linfomas con compromiso cutáneo (paniculitis), sarcoidosis (eritema nodoso). Las mialgias pueden indicar toxoplasmosis o polimiositis. La presencia de pérdida de peso y la fiebre hacen pensar en enfermedades sistémicas importantes (tuberculosis, histoplasmosis, linfomas y cáncer solido) ${ }^{(7-9)}$. Nuestro paciente era negativo para ELISA VIH y tampoco presentó signos de otras enfermedades infecciosas ni autoinmunes.

Para complementar la estrategia heurística de diagnóstico, se realizó un ejercicio pedagógico de diagnóstico basado en la mejor evidencia disponible, según las características de las adenopatías. En general los médicos son buenos en el reconocimiento de patrones (heurístico, agrupamiento de signos y síntomas) que permiten llegar a una conclusión diagnóstica; sin embargo, predecir con base en signos y síntomas con probabilidades exactas es difícil, ya que para hacerlo es necesario conocer los estudios de la prueba que evalúen la sensibilidad, especificidad $y$ razones de probabilidad (Iikelihood ratio, LR), de modo que se obtenga un valor especifico al signo y al síntoma.

predecir qué pacientes con adenopatías requieren una biopsia ha sido evaluado en diferentes estudios. En un estudio se encontraron 6 variables independientes que predicen la probabilidad de malignidad y la necesidad de biopsia por escisión: edad mayor de 40 años, ausencia de dolor, tamaño del ganglio mayor a $1 \mathrm{~cm}$, prurito generalizado, localización supraclavicular y textura fibrosa ${ }^{(7-8)}$. Para el caso clínico se realizó un ejercicio de diagnóstico, no solo heurístico, sino probabilístico donde con cada LR se efectuó una predicción de alta probabilidad de malignidad con las características de las adenopatías de este paciente (Tabla 3). La biopsia confirmó un linfoma Hodgkin asociado a la infección por el virus de Epstein-Barr ${ }^{(9)}$.

\section{Linfoma de Hodgkin y su asociación con la infección por el virus Epstein-Barr y estrés emocional}

EI linfoma de Hodgkin es un tipo de linfoma B frecuente en adultos jóvenes $y$ adolescentes, presenta una edad media de 32 años al realizar el diagnóstico y una incidencia de 8.000 casos anuales nuevos en Estados Unidos ${ }^{(2)}$. El diagnóstico de linfoma de Hodgrkin se sospecha por los hallazgos clínicos en pacientes con adenopatías generalizadas y síntomas B. Se confirma mediante el estudio histopatológico de los ganglios y la inmunofenotipificación. Una de las características histopatológicas más importantes del linfoma de Hodgkin son las células de Reed-Sternberg, estas presentan núcleos bilobulados tipo célula con "ojos de búho" ${ }^{2,10)}$ (Figura 3).

En el caso del paciente el diagnóstico se da en la sexta década de la vida con un cuadro clínico de adenopatías generalizadas de tamaño variable, ubicadas en el área preauricular, cervical, submentoniana, epitroclear y axilar bilateral, esplenomegalia aproximadamente cuatro centímetros debajo del reborde costal izquierdo, fiebre y pérdida de peso, como síntomas B. EI método diagnóstico de reconocimiento de patrones y probabilístico coincidieron en que se trataba de una enfermedad grave (linfoma). El panel básico de inmunotipificación del ganglio biopsiado confirmó que se trataba de un linfoma de Hodgkin. Adicionalmente, la presencia del marcador LMP-12 indica una infección por el virus de Epstein-Barr. Esta es una proteína latente de membrana que actúa rescatando a las células B de la apoptosis e induciendo la síntesis de interleuquina 10 (IL-10) ${ }^{(11-14)}$. Cerca del $98 \%$ de la población general está infectada con este virus, el cual puede permanecer latente durante años y reactivarse en estados de inmunosupresión generando linfomagénesis ${ }^{(15)}$

En el paciente la condición que probablemente pudo disminuir su respuesta inmunológica fue el estrés 
emocional ante el fallecimiento de su esposa, el cual puede generar un incremento de la actividad del eje hipotálamo-hipófisis-adrenal, secretando mayores cantidades de corticosteroides que inhiben la producción de interleucinas e interferones ${ }^{(16-21)}$. Existe evidencia que soporta la existencia de una relación negativa entre el estrés y la funcionalidad de las células del sistema inmune, dando a entender que el estrés, por tanto, es un factor inmunosupresor. El estrés se encuentra negativamente relacionado con la proliferación de linfocitos estimulados, así como con la actividad de las células NK. También pudo demostrarse que el estrés y el número de células $B$, células $\mathrm{T}$ ayudadoras, células T supresoras o citotóxicas y linfocitos T granulares, como las células NK, tienen una relación inversamente proporcional ${ }^{(20)}$.

También existe una relación relativamente difusa entre los niveles de anticuerpos contra virus latentes en personas expuestas a situaciones de estrés de carácter personal o social. Los estudios indican que la relación entre estrés e inmunoglogulina A es mucho más consistente que la relación con las inmunoglobulinas $M$ y G, encontrándose un incremento parcial en la concentración de inmunoglobulina A. Se ha constatado que las concentraciones de anticuerpos frente a situaciones interpersonales de estrés y de larga duración se encuentran elevadas, hecho que lleva a la interpretación de la incapacidad del sistema inmune para mantener el control de estos virus, como podría haber sucedido con el paciente del presente caso ${ }^{(20)}$. La inmunosupresión asociada con el estrés emocional y la diabetes mal controlada posiblemente alteraron el equilibrio entre el virus y el huésped a favor del virus (21), al comprometer la capacidad de respuesta de las células T, resultando en la reactivación de la infección previa y, por tanto, la proliferación sin control de linfocitos T infectados ${ }^{(20)}$

Asimismo, se ha verificado que las condiciones sociales, las relaciones interpersonales y la soledad afectan notablemente la latencia de las infecciones por algunos virus herpes. Se demostró que aquellas personas con un puntaje alto en la escala de UCLA (University of California at Los Angeles), un instrumento para medir globalmente la sensación de soledad que consta de 3 dimensiones: percepción subjetiva de soledad, apoyo familiar $y$ apoyo social, con 2 factores: la intimidad con otros y la sociabilidad ${ }^{(22)}$, tienen títulos elevados de anticuerpos contra el virus de Epstein-Barr. Se cree que cuando esto sucede en pacientes que no tienen malignidad se debe a una respuesta a la expresión potenciada del virus latente, debido a la disfunción de diferentes poblaciones celulares de células $\mathrm{T}^{(23-24)}$.

\section{CONCLUSIÓN}

El $\nabla$ semestre de medicina de la Universidad de Antioquia constituye el puente entre lo básico y lo clínico. El enfoque de los pacientes con adenomegalias supone la integración de áreas básicas de Inmunología, Virología, y Patología con áreas clínicas como Semiología, Medicina interna y debe incluir un completo interrogatorio con el fin de identificar la sintomatología asociada, así como una completa exploración física de las adenomegalias. Se presentó el caso de un paciente con linfoma Hodgkin asociado con el virus de Epstein-Barr quien presentaba, además, síntomas B y constitucionales. Como antecedentes están la diabetes mellitus y el duelo por el fallecimiento de su esposa, que pueden haber sido estímulos de estrés emocional que pueden determinar un estado de inmunosupresión. La estrategia de estudio de casos en tiempo real que sigue la evolución del paciente propicia a los estudiantes de medicina la adquisición de aprendizajes siønificativos e integrativos.

\section{AGRADECIMIENTOS}

Al Departamento de Patología, Facultad de Medicina, Universidad de Antioquia. A la Dra. Elsa María Villegas, profesora de Bioética y al Dr. Javier Rendón, Profesor, hematopatólogo, Departamento de Patología, Universidad de Antioquia.

\section{CONFLICTOS DE INTERESES}

Ninguno por declarar.

\section{REFERENCIAS BIBLIOGRÁFICAS}

1. Kierzenbaum AL, Tres LL. Sistema inmuno-linfático. En: Kierszenbaum AL. Histología y biología celular. 3a ed. España: Elsevier; 2012. p. 303-55. 
2. Kumar $\nabla$, Abbas AK, Aster JC. Enfermedades de Ios leucocitos, ganglios linfáticos, bazo y timo. En: Robbins y Cotran. Patología estructural y funcional. 9a ed. Barcelona: Elsevier; 2015. p. 579-626.

3. Henry PH, Longo DL. Linfadenopatía y esplenomegalia. En: Harrison. Principios de medicina interna. 18a ed. México: McGraw-Hill; 2012. p. 465-71.

4. Jane WB, Dains JE, Flynn JA, Solomon BS. Stewart RW. Sistema linfático. En: Manual Seidel de exploración física. 8a ed. España: Elsevier; 2015. p. 166-83.

5. Raluy Domínguez JJ, Rodríguez LM. A partir de un síntoma: adenopatías [Internet]. [Consultado 2017 sep 15]. Disponible en: http://cort.as/-ItrP

6. Iribarren JR, Aguirre H. Adenopatías [Internet]. [Consultado 2017 sep 15]. Disponible en: http://cort.as/-Itrb

7. McGee S. Peripheral Lymphandenopathy. En: Evidence-based Physical Diagnosis. 3a ed. Filadelfia: Elsevier; 2012. Pag 215-26.

8. Ferrer RL. Evaluation of peripheral Iymphadenopathy in adults [Internet]. [Consultado 2017 sep 21]. Disponible en: http://cort.as/-IvpH

9. Laso Guzmán FJ. Adenopatías y esplenomegalia. En: Diagnóstico diferencial en medicina interna. 4a ed. España: Elsevier 2013. p. 313-20.

10. Klatt E. Hematopatología. En: Robbins y Contran. Atlas de anatomía patológica. 3a ed. España: Elsevier; 2007. p. 69-95.

11. Lara Torres CO, Ortiz-Hidalgo C. Diagnóstico histopatológico e inmunohistoquímico del linfoma de Hodgrkin y su diagnóstico diferencial. Rev Latinoam Patol. 2009;45;(3):126-40.

12. Desouki MM, Post GR, Cherry D, Lazarchick J. PAX5: A Valuable Immunohistochemical Marker in the Differential Diagnosis of Lymphoid Neoplasms. Clin Med Res. 2010;8(2):84-8. DOI 10.3121/cmr.2010.891.

13. NCBI. TNFRSF8 Miembro 8 de la superfamilia del receptor de TNF [ Homo sapiens (humano)] [internet]. Maryland: NCBI; c1998 [actualizado 2018 oct 8].
[Consultado 2018 febrero 11]. Disponible en: http:// cort.as/-IXQR

14. GeneCards Human gene database [internet]. Rehovot: Weizmann Institute of Science; c2005. [Consultado 2018 feb 11]. Disponible en: http://cort.as/-IXQg

15. Beltramino M P, Clement M, Gatica Valdés M. Virus de Epstein Barr y su relación con el desarrollo de enfermedades linfoproliferativas. Hematologia. 2005;9(2):40-54.

16. Miranda-Garduño LM, Reza-Albarrán A. Obesidad, inflamación y diabetes. Gac Méd Méx. 2008;144(1):39-46.

17. Inzucchi SE, Sherwin R.S. Diabetes Mellitus Tipo 1. En: Goldman L, Ausiello D. Tratado de Medicina Interna. 25a ed. España: EIsevier; 2016. p. 1268-73.

18. Godbout JP Glase R. Stress-Induced Immune Dysregulation: Implications for Wound Healing, Infectious Disease and Cancer. J Neuroimmune Pharmacol. 2006;I(4):421-7. DOI 10.1007/s1 1481-006-9036-0.

19. Sánchez Segura M, González García RM, Marsán Suárez $\nabla$, Macías Abraham $C$. Asociación entre el estrés y las enfermedades infecciosas, autoinmunes, neoplásicas y cardiovasculares. Rev Cubana Hematol Inmunol Hemoter. 2006;22(3).

20. Herbert TB, Cohen S. Stress and immunity in humans: A Meta-Analytic Review. Psychosomatic medicine. Psychosom Med. 1993;55(4):364-79.

21. Gómez González B, Escobar A. Estrés y sistema inmune. Rev. Mex. Neuroci. 2006;7(1):30-8.

22. Comunidad Virtual de Anatomía Patológica [Internet]. Castilla: Universidad de Castilla de la Mancha; c1998. [Consultado 2018 junio 3] Disponible en: http://cort.as/-Iw61

23. Glaser R, Kiecolt-Glaser JK. Stress-induced immune dysfunction: implications for health. Nat Rev Immunol. 2005;5(3):243-51. DOI 10.1038/nri1571.

24. Glaser R, Kiecolt-Glaser JK, Speicher CE, Holliday JE. Stress, loneliness, and changes in herpesvirus latency. J Behav Med. 1985;8(3):249-60. 